\title{
Hematological Parameters Characteristics in Children with Obstructive Sleep Apnea with Obesity
}

This article was published in the following Dove Press journal: Risk Management and Healthcare Policy

\author{
Tian Shen ${ }^{1, *}$ \\ Jing Wang ${ }^{1} *$ \\ Wen Yang' \\ Linke $\mathrm{Li}^{\prime}$ \\ Yixin Qiao' \\ Xiaohong Yan' \\ Min Chen ${ }^{2}$ \\ Xiangdong Tang ${ }^{3}$ \\ Jian Zou' \\ Yu Zhao' \\ 'Department of Otorhinolaryngology \\ Head and Neck Surgery, West China \\ Hospital, Sichuan University, Chengdu, \\ Sichuan, People's Republic of China; \\ ${ }^{2}$ Department of Otorhinolaryngology \\ Head and Neck Surgery, Chengdu \\ Shangjin Nanfu Hospital, West China \\ Hospital, Sichuan University, Chengdu, \\ Sichuan, People's Republic of China; \\ ${ }^{3}$ Sleep Medicine Center, West China \\ Hospital, Sichuan University, Chengdu, \\ Sichuan, People's Republic of China \\ *These authors contributed equally to \\ this work
}

\begin{abstract}
Objective: To investigate the possible correlation between obesity and hematological parameters in children with obstructive sleep apnea (OSA).

Methods: A total of 460 children was initially included in our study, which were divided into children with OSA and children without OSA. Multiple analysis was performed for obesity by adjusting confounding factors such as age and gender in 460 children. Further, to minimize the influence of confounding factors and selective bias, propensity score matching (PSM) was performed in children with OSA. Hematological parameters such as inflammatory and coagulable parameters were compared between the normal weight children with OSA and the obese children with OSA following PSM.

Results: OSA (OR $=3.061 ; P<0.001 ; 95 \% \mathrm{CI}, 1.772-5.288)$ represented an independent risk factor for obesity. Besides, the obese children with OSA had higher levels of white blood cell (WBC) $(P<0.001)$, neutrophil (NEUT) $(P<0.001)$, neutrophil-lymphocyte ratio (NLR) $(P=0.006)$, fibrinogen (FIB) $(P=0.033)$, while had a lower level of activated partial thromboplastin time (APTT) $(P=0.048)$. No significant differences were observed in other hematological parameters. In linear regression, the results indicated that the levels of $\mathrm{WBC}\left(\mathrm{R}^{2}=\right.$ 0.123 , Beta $=0.289, \mathrm{P}<0.001)$, NEUT $\left(\mathrm{R}^{2}=0.124\right.$, Beta $\left.=0.282, \mathrm{P}<0.001\right)$, NLR $\left(\mathrm{R}^{2}=\right.$ 0.105 , Beta $=0.184, \mathrm{P}=0.026)$ and FIB $\left(\mathrm{R}^{2}=0.086\right.$, Beta $\left.=0.246, \mathrm{P}=0.003\right)$ were positively correlated with BMI, while the level of APTT $\left(\mathrm{R}^{2}=0.057\right.$, Beta $\left.=-0.171, \mathrm{P}=0.044\right)$ was significantly negatively correlated with BMI.
\end{abstract}

Conclusion: OSA was an independent risk factor contributing to obesity. WBC, NEUT, NLR, FIB and APTT are correlated with obesity in children with OSA (aged from 2 to 14 years). These indicators could be used to estimate the status of inflammation and hypercoagulation in the obese children with OSA.

Keywords: obstructive sleep apnea, obesity, propensity score matching, hematological parameter, inflammation, hypercoagulation

\section{Introduction}

Obstructive sleep apnea (OSA) is a condition secondary to partial or complete obstruction of upper airway during sleep. This condition shows a prevalence of $1-5 \%$ in children. ${ }^{1}$ Due to periodic upper airway collapse and nocturnal hypoxia, the development of metabolic and inflammatory system responses has altered. ${ }^{2}$ Several studies focused on OSA have proven this condition was closely related to chronic systematic inflammation. Besides, chronic inflammatory responses are often associated with the activation of coagulation. $^{3}$
Correspondence: Yu Zhao; Jian Zou Department of Otolaryngology Head and Neck Surgery, West China Hospital, Sichuan University, Chengdu, Sichuan, People's Republic of China

Tel +86-I898060I4I 0; +86-I8980605883

Email yutzhao@।63.com;

zoujian926@163.com
Risk Management and Healthcare Policy 202I:I4 I0I5-I023 
In recent decades, obesity has become a serious public health concern, and is also the most important risk factor for OSA both in adults and children. ${ }^{4,5}$ As the result, approximately $50 \%$ to $60 \%$ of obese individuals have OSA. ${ }^{6}$ Several studies have concluded that increases in weight are associated with an increasing prevalence and severity of OSA. $^{7}$ Besides, it seems that there is a bidirectional association between obesity and OSA since OSA has a number of obesity-inducing effects, such as decreased physical activity and energy metabolism. ${ }^{8}$

Notwithstanding previous mentioned studies have described the relationship between OSA and inflammation, obesity and inflammation, respectively, ${ }^{2,9}$ few studies focus on the inflammatory status in children affected with both OSA and obesity. Many easily accessible, relatively cheap and readily-measured laboratory parameters have been used to estimate systematic inflammation in studies, such as red cell distribution width (RDW), ${ }^{10}$ neutrophil-lymphocyte ratio (NLR), ${ }^{11}$ platelet-lymphocyte ratio (PLR). ${ }^{12}$ We hypothesized that obesity would aggravate the inflammatory status in children with OSA. To verify this speculation, we explore the correlation between the hematological parameters and obesity in the children with OSA in this study.

\section{Methods}

\section{Participants}

Written informed consent was obtained from all children's parents. This study was approved by the Ethics Committee of West China Hospital, Sichuan University (Approval No.2018-146). We included children who visited the department of Otorhinolaryngology of West China Hospital from January 2013 and May 2019. The included criteria were defined as: 1) children underwent complete performance of polysomnography (PSG) if they were suspected to have OSA; 2) well-documented demographic data (gender, age and body mass index [BMI]). The exclusion criteria included craniofacial malformation, any genetic or immunodeficiency disease, or acute upper respiratory infection.

\section{Study Design}

The children with OSA were defined as an apnea-hypopnea index (AHI) $\geq 1$ event per hour and minimum oxygen saturation of arterial blood $\left(\mathrm{Min} \mathrm{SaO}_{2}\right)<92 \%$. According to AHI, we divided the whole children into two groups (children with OSA group and children without OSA). Similarly, by age- and gender-corrected BMI using the Chinese guidelines, ${ }^{13,14}$ these children were divided into the normal weight children and the obese children. Furthermore, we explored the correlation between obesity and hematological parameters by using propensity score matching (PSM) in these children with OSA.

Hereinafter, the normal weight group was considered as the normal weight children with OSA and the obese group was considered as the obese children with OSA.

\section{Clinical Data}

Demographic data (gender, age, body mass index), PSG data and laboratory parameters were collected and registered. Venous blood was obtained from each child in EDTA-K2 anticoagulation collection tube. All blood specimens were performed within 4 hours by clinical laboratory professionals.

\section{Statistical Analysis}

Statistical analysis was performed by SPSS version 24.0. $P<0.05$ was considered statistically significant.

The continuous variables were tested for normal distribution with the Kolmogorov-Smirnov test. For continuous variables, groups were compared by the Mann-Whitney $U$-test or independent $t$-test, as appropriate. The continuous variables were displayed as mean \pm standard deviations, while the categorical variables used chi-square test and were displayed by frequency and percentage.

Multiple analysis with dummy-variable binary logistic regression was performed for obesity by adjusting confounding factors such as age and gender.

To minimize the influence of confounding factors and selective bias, we performed PSM in the whole children with OSA. The propensity score of covariates (gender, age, AHI) was calculated using logistic regression analysis for each child, and one to two matched analysis using nearest-neighbor matching were performed with 0.1 standard deviations of the logit of the propensity score as the caliper value.

Given the distribution of the data, Spearman's rank correlation or Pearson's correlation coefficient was used to assess correlations between BMI and hematological parameters. Unary linear regression analysis was used to quest for correlations between BMI and hematological parameters. 


\section{Results}

Demographic and Clinical Characteristics in the Whole Children

A total of 460 children (aged from 2 to 14 years) were included in this study. As shown in Table 1, there were 245 children without OSA and 215 children with OSA. There were significant differences in age $(P<0.001)$, BMI group $(P<0.001)$, gender $(P=0.002)$ and AHI $(P<0.001)$.

In the logistic regression analysis, OSA $(\mathrm{OR}=$ 3.061; $P<0.001 ; 95 \% \mathrm{CI}, 1.772-5.288)$ represented an independent risk factor for obesity (as illustrated in Figure 1).

\section{Demographic and Clinical Characteristics in the Children with OSA}

There were 215 children with OSA. As illustrated in Table 2 , in the included children, 156 were classified as the normal weight group and 59 as the obese group. AHI

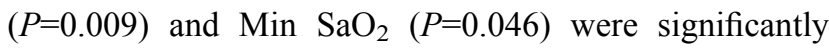
different between the two groups. We enrolled more male children than female children, but there was no statistical difference in gender ratio between the two groups.

With PSM, 97 normal weight children with OSA and 53 obese children with OSA were selected and further analyzed. There were no significant differences in age, gender, AHI or $\mathrm{Min} \mathrm{SaO}_{2}$.

Table I Demographic and Clinical Characteristic of Children with or without OSA

\begin{tabular}{|c|c|c|c|}
\hline Variables & $\begin{array}{c}\text { Children } \\
\text { without OSA }\end{array}$ & $\begin{array}{c}\text { Children } \\
\text { with OSA }\end{array}$ & $P$-value \\
\hline Children & 245 & 215 & \\
\hline Age, y & $8.05 \pm 3.24$ & $5.81 \pm 2.51$ & $<0.001^{*}$ \\
\hline BMI & $16.87 \pm 2.89$ & $17.07 \pm 3.08$ & 0.456 \\
\hline $\begin{array}{l}\text { BMI group, n\% } \\
\text { Obese } \\
\text { Normal weight }\end{array}$ & $\begin{array}{c}25(10.2 \%) \\
220(89.8 \%)\end{array}$ & $\begin{array}{c}59(27.4 \%) \\
156(72.6 \%)\end{array}$ & $<0.00 I^{*}$ \\
\hline $\begin{array}{l}\text { Gender, n\% } \\
\text { Male } \\
\text { Female }\end{array}$ & $\begin{array}{l}145(59.2 \%) \\
100(40.8 \%)\end{array}$ & $\begin{array}{c}158 \text { (73.5\%) } \\
57(26.5 \%)\end{array}$ & $0.002 *$ \\
\hline $\mathrm{AHI}$ & $0.47 \pm 0.29$ & $18.64 \pm 21.82$ & $<0.00 I^{*}$ \\
\hline
\end{tabular}

Note: $* P<0.05$.

Abbreviations: OSA, obstructive sleep apnea; BMI, body mass index; $\mathrm{AHI}$, apneahypopnea index.

\section{Analysis of Hematological Parameters in Two Groups After Following PSM}

From Table 3, the obese group had higher levels of white blood cell (WBC) $(P<0.001)$, neutrophil (NEUT) $(P<0.001), \quad$ NLR $\quad(P=0.006)$ and fibrinogen (FIB) $(P=0.033)$. However, the obese children with OSA had a lower level of activated partial thromboplastin time (APTT) $(P=0.048)$ than the normal weight group. No such significant differences were observed in red blood cell (RBC), hemoglobin concentration (HGB), hematocrit (HCT), RDW coefficient of variation (RDW-CV), platelet (PLT), PLR, prothrombin time (PT), international normalized ratio (INR) or thrombin time (TT).

\section{Correlation Between BMI and}

\section{Hematological Parameters in Two Groups After Following PSM}

Figure 2 presents the correlation between BMI and the levels of WBC, NEUT, NLR, FIB and APTT, respectively. The levels of WBC and NEUT showed significant positive correlation with BMI $(\mathrm{r}=0.275 ; P=0.001 ; 95 \% \mathrm{CI}, 0$.$116-0.421$ and $\mathrm{r}=0.292 ; P<0.001 ; 95 \% \mathrm{CI}, 0.134-0.436$, respectively). In addition, the levels of NLR and FIB were also positively correlated with BMI $(\mathrm{r}=0.231 ; P=0.005$; 95\% CI, $0.067-0.380$ and $\mathrm{r}=0.183 ; P=0.025 ; 95 \% \mathrm{CI}$, $0.019-0.338$, respectively). On the contrary, the level of APTT was observed a negative correlation with BMI $(\mathrm{r}=$ $-0.235 ; P=0.004 ; 95 \% \mathrm{CI},-0.385--0.073)$. The other parameters did not show any statistical correlations with BMI.

\section{Unary Linear Regression}

The results of the multiple linear regression analysis are presented in Table 4, which used BMI as the independent variable and hematological parameters as the dependent variable among the children with OSA after following PSM. The results indicated that the levels of $\mathrm{WBC}\left(\mathrm{R}^{2}=\right.$ 0.123 , Beta $=0.289, P<0.001)$, NEUT $\left(\mathrm{R}^{2}=0.124\right.$, Beta $=$ $0.282, P<0.001)$, NLR $\left(\mathrm{R}^{2}=0.105\right.$, Beta $=0.184$, $P=0.026)$ and FIB $\left(\mathrm{R}^{2}=0.086\right.$, Beta $\left.=0.246, P=0.003\right)$ were positively correlated with BMI, while the level of APTT $\left(\mathrm{R}^{2}=0.057\right.$, Beta $\left.=-0.171, P=0.044\right)$ was negatively correlated with BMI.

\section{Discussion}

In this study, OSA was an independent risk factor contributing to obesity. In comparison to the normal weight 


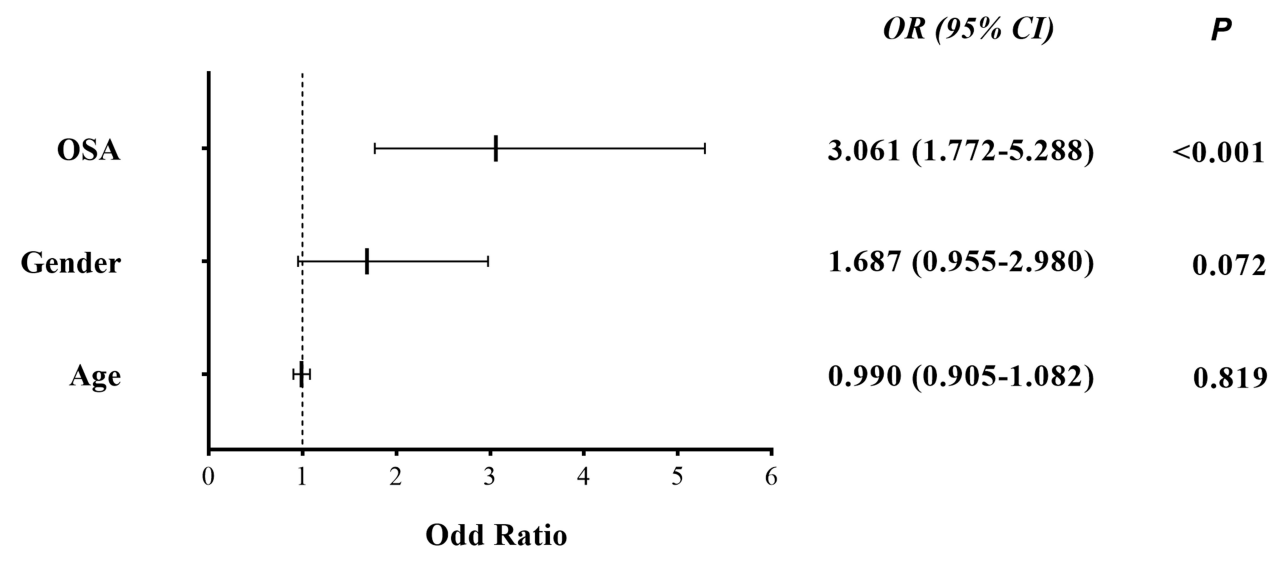

Figure I Analysis with dummy-variable binary logistic regression of factors contributing to obesity in children.

group, the obese group had higher levels of WBC, NEUT and NLR. Significant positive correlations were observed between the levels of WBC, NEUT, NLR and BMI in children with OSA, which indicated obesity might aggravate the inflammatory status in the children with OSA. Besides, the obese group had a higher level of FIB and a lower level of APTT than the normal weight group. And BMI was found positively correlated with the level of FIB, while negatively correlated with the level of APTT. The results suggested that the obese children with OSA were predisposed to present coagulation disorder.

Obesity, characterized by recurrent narrowing in the upper airway structure, is considered as one of the risk factors of OSA. ${ }^{4}$ Alterations caused by fat deposition in oropharynx elicit intermittent hypoxia and sleep fragmentation, and thereby increased the risk of OSA. Visceral obesity is another factor that restricts lung expansion and is considered as another risk factor in OSA. ${ }^{15} \mathrm{~A}$ study by Quintas-Neves reported that an increase of 6 units in BMI was associated with a four-fold risk of OSA. ${ }^{16}$ Besides, bariatric surgery was confirmed to be effective in alleviating the severity of OSA.

On the other hand, OSA also exert many promoting effects on obesity. In Grote et al study, patients with OSA were liable to fatigue and reduced physical activity. ${ }^{17}$ This reduced physical activity can play a role in predisposing patients with OSA to obesity. Some humoral mechanisms, such as leptin and ghrelin, could cause weight gain. ${ }^{18}$ An increased leptin and ghrelin can contribute to decreased satiety and increased hunger for adults with OSA by Shechter ${ }^{18}$ Studies have shown that continuous positive airway pressure therapy was helpful to reduce body weight and the level of leptin in obese adults with OSA. $^{19,20}$ There are also several studies focused on

Table 2 Demographic and Clinical Characteristics of Children Before and After Propensity Score Matched Analysis

\begin{tabular}{|c|c|c|c|c|c|c|}
\hline \multirow[t]{2}{*}{ Variables } & \multicolumn{2}{|c|}{ Before PSM } & \multirow[t]{2}{*}{$P$-value } & \multicolumn{2}{|c|}{ After PSM } & \multirow[t]{2}{*}{$P$-value } \\
\hline & Normal Weight Group & Obese Group & & Normal Weight Group & Obese Group & \\
\hline Children & 156 & 59 & & 97 & 53 & \\
\hline Age, y & $5.79 \pm 2.51$ & $5.86 \pm 2.52$ & 0.764 & $5.78 \pm 2.56$ & $5.57 \pm 2.23$ & 0.604 \\
\hline BMI & $15.54 \pm 1.13$ & $21.13 \pm 2.90$ & $<0.001 *$ & $15.53 \pm 1.23$ & $20.97 \pm 2.79$ & $<0.00 I^{*}$ \\
\hline Gender, n\% & & & 0.360 & & & 0.688 \\
\hline Male & $112(71.8 \%)$ & 46 (78.0\%) & & $73(75.3 \%)$ & 42 (79.2\%) & \\
\hline Female & $44(28.2 \%)$ & $13(22.0 \%)$ & & $24(24.7 \%)$ & II (20.8\%) & \\
\hline $\mathrm{AHI}$ & $16.24 \pm 19.66$ & $25.00 \pm 25.83$ & $0.009 *$ & $16.74 \pm 16.55$ & $18.78 \pm 17.62$ & 0.481 \\
\hline $\mathrm{Min} \mathrm{SaO}_{2}, \%$ & $74.84 \pm 12.74$ & $70.85 \pm 13.66$ & $0.046 *$ & $73.66 \pm|3.4|$ & $76.72 \pm 11.82$ & 0.166 \\
\hline
\end{tabular}

Note: $* P<0.05$

Abbreviations: PSM, propensity score matching; $\mathrm{AHI}$, apnea-hypopnea index; $\mathrm{Min} \mathrm{SaO}_{2}$, minimum oxygen saturation of arterial blood. 
Table 3 Comparison of Hematological Characteristics of the Patients Between the Normal Weight Group and the Obese Group

\begin{tabular}{|c|c|c|c|}
\hline Variables & $\begin{array}{c}\text { Normal Weight } \\
\text { Group (N=97) }\end{array}$ & $\begin{array}{l}\text { Obese Group } \\
\qquad(N=53)\end{array}$ & $P$-value \\
\hline $\operatorname{RBC}\left(10^{12} / \mathrm{L}\right)$ & $4.81 \pm 0.33$ & $4.94 \pm 0.46$ & 0.079 \\
\hline HGB $(g / L)$ & $|3| .82 \pm 8.70$ & $132.53 \pm 9.07$ & 0.642 \\
\hline HCT (L/L) & $0.40 \pm 0.03$ & $0.40 \pm 0.03$ & 0.600 \\
\hline RDW-CV (\%) & $13.19 \pm 1.08$ & $13.44 \pm 1.09$ & 0.175 \\
\hline PLT $\left(10^{9} / \mathrm{L}\right)$ & $307.28 \pm 71.88$ & $313.72 \pm 101.95$ & 0.653 \\
\hline WBC $\left(10^{9} / \mathrm{L}\right)$ & $7.54 \pm 1.99$ & $8.91 \pm 2.59$ & $<0.00 I^{*}$ \\
\hline NEUT $\left(10^{9} / \mathrm{L}\right)$ & $3.30 \pm 1.56$ & $4.47 \pm 2.10$ & $<0.00 I^{*}$ \\
\hline $\operatorname{LYM}\left(10^{9} / \mathrm{L}\right)$ & $3.42 \pm 0.94$ & $3.62 \pm 1.14$ & 0.246 \\
\hline NLR & $1.04 \pm 0.57$ & $1.33 \pm 0.68$ & $0.006 *$ \\
\hline PLR & $94.60 \pm 28.25$ & $93.65 \pm 36.83$ & 0.860 \\
\hline PT (s) & $11.47 \pm 0.73$ & $11.38 \pm 0.66$ & 0.427 \\
\hline INR & $0.99 \pm 0.06$ & $0.98 \pm 0.06$ & 0.604 \\
\hline APTT (s) & $31.34 \pm 4.14$ & $29.95 \pm 3.95$ & $0.048^{*}$ \\
\hline TT (s) & $19.86 \pm 1.40$ & $19.76 \pm 1.38$ & 0.665 \\
\hline FIB $(g / L)$ & $2.44 \pm 0.48$ & $2.66 \pm 0.63$ & $0.033^{*}$ \\
\hline
\end{tabular}

Note: $* P<0.05$.

Abbreviations: RBC, red blood cell; HGB, hemoglobin concentration; HCT, hematocrit; RDW-CT, red cell distribution width coefficient of variation; PLT, platelet; WBC, white blood cell; NEUT, neutrophil; LYM, lymphocyte; NLR, neutrophil-to-lymphocyte ratio; PLR, platelet-to-lymphocyte ratio; PT, prothrombin time; INR, international normalized ratio; APTT, activated partial thromboplastin time; TT, thrombin time; FIB, fibrinogen.

obese children with OSA. A study found that, compared with non-obese children with OSA, obese children with OSA had higher levels of ghrelin and unhealthier physical activity. ${ }^{21}$ In addition, a large longitudinal cohort study demonstrated that children with persistent OSA had an increased risk for developing obesity. ${ }^{22}$ Our research showed a similar result that compared with children without OSA, children with OSA had a two-fold increased risk of obesity. Combined with the above paragraph, we can conclude that there is a bidirectional association between OSA and obesity.

As a result of periodic upper airway collapse, OSA rendered the normal sleep architecture fragmentation and the physiological gas exchange alteration. It was fragmented sleep architecture that led to the development of the local and systematic inflammation. ${ }^{23}$ Several studies in adults and children showed that OSA increased airway inflammation in subjects. ${ }^{24,25}$ The intermittent upper airway obstruction applied mechanical stress on the mucosa and thereby elicited local inflammation was also considered to influence systematic inflammation. ${ }^{26}$

Inflammation was an immediate protective response of the immune system to a harmful stimulus. Numerous evidences indicated that obesity was causally correlated with a chronic systematic inflammatory status. ${ }^{27,28}$ Obese people were characterized by having higher levels of inflammatory parameters than non-obese people. $^{29}$ Another study on children also showed that the obesity of childhood was associated with elevations of the antiinflammatory cytokines. ${ }^{30}$ Moreover, the loss of weight in obese people was proven to be associated with decreased inflammatory parameters. ${ }^{31}$ A feature of the obesity inflammatory status was increased infiltration of immune cells into metabolic tissues. The chronicity means that the expression of inflammatory factors in adipose tissues and increased infiltration of immune cells happen gradual instead of acute response and remains unsolved unless lose weight. Another rational mechanism was that excess nutrition may activate multiple signal pathways and thereby stimulated an inflammatory response. ${ }^{27}$ In addition, oxidative stress was regarded as a key mediator of chronic inflammatory status. ${ }^{32}$ Recently, one study reported that adipose tissues produce inflammatory factors through the activation of oxidative stress. ${ }^{33}$

Clinically, WBC was suggested as a good indicator of systematic inflammation. Some stimulation of inflammatory factors may contribute to the alterations in the level of WBC in obese adults. ${ }^{34}$ NEUT, the most abundant granulocyte in WBC, was one of the first responders of inflammatory cells to migrate toward the site of inflammation. ${ }^{35}$ Even elevating in the normal range, the level of NEUT could also be used as a predictor parameter of the inflammatory process. ${ }^{36}$ As a combination of two independent markers of inflammation, an elevated NLR ensured a higher predictive value than the standalone WBC and NEUT differential in inflammation. Of note, as a novel indicator of systematic inflammation, NLR was associated with many chronic diseases. Bozkuş ${ }^{37}$ et al found that NLR increased by the severity of obesity and therefore, by increased fat tissue and revealed that concomitant inflammatory response increased.

Our study demonstrated that the levels of WBC, NEUT and NLR in the obese children with OSA were significantly higher than those in the normal weight children with OSA. In correlation and regression analyses, these 
A

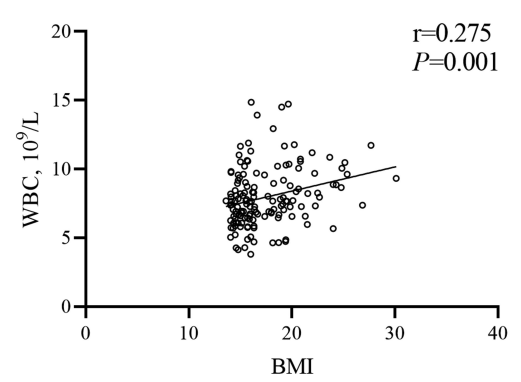

C

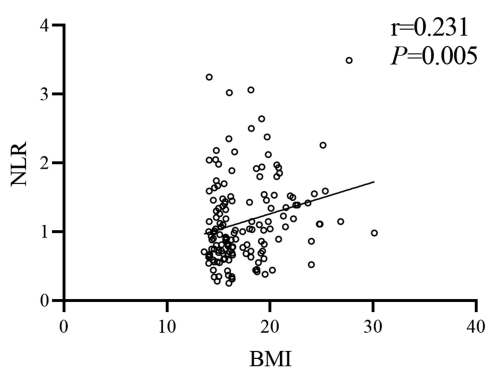

B

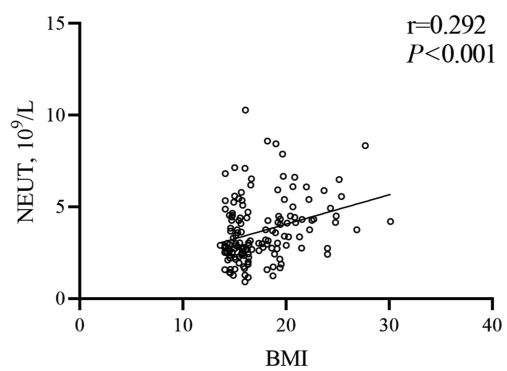

D

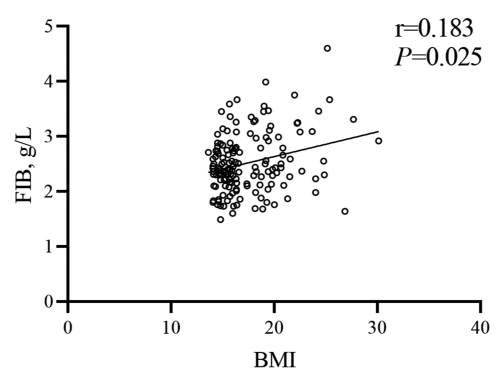

E

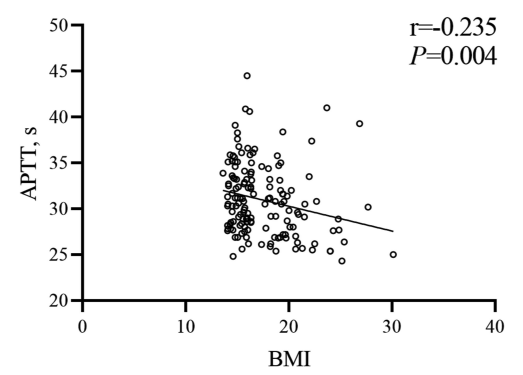

Figure 2 Correlation between BMI and hematological parameters. (A) The level of white blood cell (WBC). (B) The level of neutrophil (NEUT). (C) The ratio of neutrophil-lymphocyte (NLR). (D) The level of fibrinogen (FIB). (E) The level of activated partial thromboplastin time (APTT). BMI is calculated as body mass (kg)/height $\left(\mathrm{m}^{2}\right)$.

inflammatory parameters still exhibited positive correlated with BMI. The results suggested that obesity may aggravate the inflammatory status in the body of children on the basis of OSA, which was undoubtedly a further impact on systematic inflammation, namely, obesity could amplify the short-term and long-term damage of OSA. A chronic inflammatory status, even at low-grade, was considered as a risk factor in the development of atherosclerosis or cardiovascular disease (CVD) ${ }^{38}$ Obesity upon OSA can render endothelium dysfunction because of oxidative stress which may lead to CVD in adults. ${ }^{32,39,40}$ Therefore, the risk of obesity for CVD in children with OSA needs to be further assessed.

FIB was a coagulation factor synthesized and secreted by the liver, which mainly determined plasma viscosity and erythrocyte aggregation. A higher level of FIB elicited endothelial impairment and thrombogenesis. A study by Balagopal reported that the level of FIB showed a direct positive correlation with BMI in adults. ${ }^{41}$ Several studies on obese children showed similar result that the level of FIB in the obese children significantly exceeded in the normal weight children. ${ }^{30,42}$ In parallel to those, our study found that the level of FIB in the obese children with OSA was significantly higher than that in the normal weight children with OSA, and the level of FIB has a positive correlation with BMI. A probable mechanism was that in an inflammatory status caused by obesity as well as OSA, excess fat may contribute to more production or less clearance of FIB. ${ }^{42}$

As an important coagulation parameter, APTT reflected the intrinsic coagulation pathway maintaining the process after the initiation of coagulation. A shortened level of APTT may represent a hypercoagulable status. ${ }^{43}$ A study in obese adults showed APTT shortened with increased BMI. ${ }^{44}$ In our study, we found a similar result that in children with OSA, BMI increased with the lower level of APTT, which could be explained by the inflammatory status, because the increased FIB may automatically induce a decrease of APTT. ${ }^{30}$

Previous studies had shown an intricate relationship among OSA, obesity and inflammation. ${ }^{24,28,39}$ In our study, obvious results were observed that the levels of WBC, NEUT, NLR, FIB in the obese children with OSA were significantly higher than those in the normal weight children with OSA, while the level of APTT in the obese children with OSA was lower than that in the normal weight children with OSA. Both obesity per se and increased the severity of OSA by obesity affected the body's inflammatory status. We controlled the influence of AHI between the obese group and the normal weight group with PSM. Thus, we further concluded that obesity may have an independent effect on the exacerbation of 
Table 4 Correlation Between Hematological Parameters and BMI by Using Multiple Linear Regression Analysis Controlling for Age, Gender and AHI

\begin{tabular}{|c|c|c|c|c|}
\hline \multirow[t]{2}{*}{ Variables } & \multicolumn{4}{|c|}{ BMI } \\
\hline & $\mathbf{R}^{2}$ & B-Coefficient ( $95 \% \mathrm{Cl})$ & Beta & $P$-value \\
\hline $\operatorname{RBC}\left(10^{12} / L\right)$ & 0.124 & $0.018(-0.001-0.037)$ & 0.151 & 0.064 \\
\hline HGB (g/L) & 0.154 & $-0.027(-0.454-0.401)$ & -0.010 & 0.903 \\
\hline HCT (L/L) & 0.204 & $0<B<0.00 \mathrm{I}(-0.00 \mathrm{I}-0.00 \mathrm{I})$ & 0.003 & 0.969 \\
\hline RDW-CV (\%) & 0.078 & $0.050(-0.004-0.104)$ & 0.153 & 0.068 \\
\hline PLT (109/L) & 0.110 & I.78I (-2.372-5.935) & 0.069 & 0.398 \\
\hline WBC $\left(10^{9} / \mathrm{L}\right)$ & 0.123 & $0.206(0.092-0.320)$ & 0.289 & $<0.001 *$ \\
\hline NEUT $\left(10^{9} / \mathrm{L}\right)$ & 0.124 & $0.161(0.069-0.252)$ & 0.282 & $<0.001 *$ \\
\hline $\operatorname{LYM}\left(10^{9} / \mathrm{L}\right)$ & 0.124 & $0.045(-0.006-0.095)$ & 0.142 & 0.082 \\
\hline NLR & 0.105 & $0.035(0.004-0.0567)$ & 0.184 & $0.026 *$ \\
\hline PLR & 0.063 & $-0.347(-1.953-1.258)$ & -0.036 & 0.670 \\
\hline PT (s) & 0.009 & $-0.009(-0.046-0.028)$ & -0.040 & 0.643 \\
\hline INR & 0.010 & $0<B<0.00$ I $(-0.003-0.003)$ & -0.005 & 0.958 \\
\hline APTT (s) & 0.057 & $-0.217(-0.428--0.006)$ & $-0.17 \mid$ & $0.044 *$ \\
\hline TT (s) & 0.009 & $-0.023(-0.096-0.050)$ & -0.054 & 0.531 \\
\hline $\mathrm{FIB}(\mathrm{g} / \mathrm{L})$ & 0.086 & $0.041(0.0014-0.069)$ & 0.246 & $0.003 *$ \\
\hline
\end{tabular}

Note: $* P<0.05$.

Abbreviations: BMI, body mass index; AHI, apnea-hypopnea index; RBC, red blood cell; HGB, hemoglobin concentration; HCT, hematocrit; RDW-CT, red cell distribution width coefficient of variation; PLT, platelet; WBC, white blood cell; NEUT, neutrophil; LYM, lymphocyte; NLR, neutrophil-to-lymphocyte ratio; PLR, platelet-to-lymphocyte ratio; PT, prothrombin time; INR, international normalized ratio; APTT, activated partial thromboplastin time; TT, thrombin time; FIB, fibrinogen.

inflammatory status in children with OSA. In view of the correlation between inflammation and coagulation, we also compared the coagulable parameters in this study. An increased level of FIB and a shortened level of APTT represented hypercoagulation. Because the levels of FIB and APTT indicated the actual time of coagulation in certain circumstances, the differences in the levels of FIB and APTT were clinically significant even though data were within the reference range. In other words, obesity exacerbated inflammatory and coagulable status on the basis of OSA. Moreover, these hematological parameter levels may be involved in the subsequent potential cardiovascular comorbidities. The easily accessible, timely laboratory test to identify obese children with OSA should be considered to apply to OSA management and comorbidities in the future. Because obesity per se possessed the potential to promote cardiovascular risks from the earliest phase of life, the body weight status of children with OSA should be controlled within normal limits as much as possible to reduce the potential harmful influences of the inflammatory and hypercoagulable status. In addition, the future risks of CVD exerted by the high level of inflammation or coagulation in the obese OSA children with comorbidities need long term follow-up.

Since this study was a retrospective cohort, we failed to explore the alterations in some well-established inflammatory parameters for comparison. In addition, because the relationship between OSA and inflammatory parameters had been well described in detail in several studies, no comparison of inflammatory parameters between children with OSA and children without OSA was conducted in this paper.

\section{Conclusions}

OSA was an independent risk factor contributing to obesity. Besides, the levels of WBC, NEUT, NLR and FIB are positively correlated with obesity in children with OSA, while the level of APTT is negatively correlated with 
obesity in children with OSA. These indicators could be used to estimate the risks of inflammatory and hypercoagulable status in the obese children with OSA in outpatient follow-up. These findings may have important implications regarding obese children with OSA screening, treatment monitoring and prognosis.

\section{Abbreviations}

OSA, obstructive sleep apnea; RDW, red cell distribution width; NLR, neutrophil-lymphocyte ratio; PLR, plateletlymphocyte ratio; PSG, polysomnography; BMI, body mass index; AHI, apnea-hypopnea index; $\mathrm{Min}_{\mathrm{SaO}_{2}}$, minimum oxygen saturation of arterial blood; PSM, propensity score matching; WBC, white blood cell; NEUT, neutrophil; FIB, fibrinogen; APTT, activated partial thromboplastin time; RBC, red blood cell; HGB, hemoglobin concentration; HCT, hematocrit; RDW-CT, red cell distribution width coefficient of variation; PLT, platelet; PT, prothrombin time; INR, international normalized ratio; TT, thrombin time; CVD, cardiovascular disease.

\section{Ethics and Consent}

This study was approved by the Ethics Committee of West China Hospital, Sichuan University (Approval No.2018146) and performed in compliance with the Declaration of Helsinki. All children involved gave their parents' written consent to review their medical data.

\section{Funding}

This work was partly supported by the Post-doctoral Research and Development Fund project of Sichuan University (NO. 2019HXBH093; Jing Wang).

\section{Disclosure}

The authors report no conflicts of interest in this work.

\section{References}

1. Li Z, Celestin J, Lockey RF. Pediatric sleep apnea syndrome: an update. J Allergy Clin Immunol Pract. 2016;4(5):852-861. doi:10.10 16/j.jaip.2016.02.022

2. Faraut B, Boudjeltia KZ, Vanhamme L, Kerkhofs M. Immune, inflammatory and cardiovascular consequences of sleep restriction and recovery. Sleep Med Rev. 2012;16(2):137-149. doi:10.1016/j.smrv.20 11.05.001

3. Hong SN, Yun HC, Yoo JH, Lee SH. Association between hypercoagulability and severe obstructive sleep apnea. JAMA Otolaryngol Head Neck Surg. 2017;143(10):996-1002. doi:10.1001/jamaoto.2017.1367

4. Lavie CJ, Milani RV, Ventura HO. Obesity and cardiovascular disease: risk factor, paradox, and impact of weight loss. $\mathrm{J} \mathrm{Am} \mathrm{Coll} \mathrm{Cardiol.}$ 2009;53(21):1925-1932. doi:10.1016/j.jacc.2008.12.068
5. Young T, Skatrud J, Peppard PE. Risk factors for obstructive sleep apnea in adults. JAMA. 2004;291(16):2013-2016. doi:10.1001/jama. 291.16.2013

6. Verhulst SL, Van Gaal L, De Backer W, Desager K. The prevalence, anatomical correlates and treatment of sleep-disordered breathing in obese children and adolescents. Sleep Med Rev. 2008;12(5):339-346. doi:10.1016/j.smrv.2007.11.002

7. Young T, Shahar E, Nieto FJ, et al. Predictors of sleep-disordered breathing in community-dwelling adults: the Sleep Heart Health Study. Arch Intern Med. 2002;162(8):893-900. doi:10.1001/archinte. 162.8.893

8. Shah N, Roux F. The relationship of obesity and obstructive sleep apnea. Clin Chest Med. 2009;30(3):455-65, vii. doi:10.1016/j.ccm.20 09.05 .012

9. Sacheck J. Pediatric obesity: an inflammatory condition. JPEN J Parenter Enteral Nutr. 2008;32(6):633-637. doi:10.1177/0148607108324876

10. Salvagno GL, Sanchis-Gomar F, Picanza A, Lippi G. Red blood cell distribution width: a simple parameter with multiple clinical applications. Crit Rev Clin Lab Sci. 2015;52(2):86-105. doi:10.31 09/10408363.2014.992064

11. Uygur F, Tanriverdi H, Aktop Z, et al. The neutrophil-to-lymphocyte ratio in patients with obstructive sleep apnoea syndrome and its relationship with cardiovascular disease. Heart Lung. 2016;45 (2):121-125. doi:10.1016/j.hrtlng.2016.01.002

12. Song YJ, Kwon JH, Kim JY, Kim BY, Cho KI. The platelet-tolymphocyte ratio reflects the severity of obstructive sleep apnea syndrome and concurrent hypertension. Clin Hypertens. 2015;22:1. doi:10.1186/s40885-015-0036-3

13. Hui L, Cheng-Ye J, Xin-Nan Z, Ya-Qin Z. [Height and weight standardized growth charts for Chinese children and adolescents aged 0 to 18 years]. Zhonghua Er Ke Za Zhi. 2009;47(7). Chinese.

14. Kuczmarski RJ, Ogden CL, Guo SS, et al. 2000 CDC growth Charts for the United States: methods and development. Vital Health Stat. 2002;11(246):1-190.

15. Madani M, Madani F. The pandemic of obesity and its relationship to sleep apnea. Atlas Oral Maxillofac Surg Clin North Am. 2007;15 (2):81-88. doi:10.1016/j.cxom.2007.05.005

16. Quintas-Neves M, Preto J, Drummond M. Assessment of bariatric surgery efficacy on Obstructive Sleep Apnea (OSA). Rev Port Pneumol. 2016;22(6):331-336. doi:10.1016/j.rppnen.2016.05.006

17. Grote L, Hedner J, Peter JH. The heart rate response to exercise is blunted in patients with sleep-related breathing disorder. Cardiology. 2004;102(2):93-99. doi:10.1159/000077911

18. Shechter A. Obstructive sleep apnea and energy balance regulation: a systematic review. Sleep Med Rev. 2017;34:59-69. doi:10.1016/j. smrv.2016.07.001

19. Loube DI, Loube AA, Erman MK. Continuous positive airway pressure treatment results in weight less in obese and overweight patients with obstructive sleep apnea. J Am Diet Assoc. 1997;97(8):896-897. doi:10.1016/S0002-8223(97)00220-4

20. Chin K, Shimizu K, Nakamura T, et al. Changes in intra-abdominal visceral fat and serum leptin levels in patients with obstructive sleep apnea syndrome following nasal continuous positive airway pressure therapy. Circulation. 1999;100(7):706-712. doi:10.1161/01.CIR.100. 7.706

21. Spruyt K, Sans Capdevila O, Serpero LD, Kheirandish-Gozal L, Gozal D. Dietary and physical activity patterns in children with obstructive sleep apnea. J Pediatr. 2010;156(5):724-30, 730.e1730.e3. doi:10.1016/j.jpeds.2009.11.010

22. Goodwin JL, Vasquez MM, Silva GE, Quan SF. Incidence and remission of sleep-disordered breathing and related symptoms in 6- to 17-year old children-the Tucson Children's Assessment of Sleep Apnea Study. J Pediatr. 2010;157(1):57-61. doi:10.1016/j.jpeds.2010.01.033

23. Williams A, Scharf SM. Obstructive sleep apnea, cardiovascular disease, and inflammation-is NF-kappaB the key. Sleep Breath. 2007;11(2):69-76. doi:10.1007/s11325-007-0106-1 
24. Verhulst SL, Aerts L, Jacobs S, et al. Sleep-disordered breathing, obesity, and airway inflammation in children and adolescents. Chest. 2008;134(6):1169-1175. doi:10.1378/chest.08-0535

25. Petrosyan M, Perraki E, Simoes D, et al. Exhaled breath markers in patients with obstructive sleep apnoea. Sleep Breath. 2008;12 (3):207-215. doi:10.1007/s11325-007-0160-8

26. Almendros I, Carreras A, Ramírez J, Montserrat JM, Navajas D, Farré R. Upper airway collapse and reopening induce inflammation in a sleep apnoea model. Eur Respir J. 2008;32(2):399-404. doi:10. $1183 / 09031936.00161607$

27. Hotamisligil GS. Inflammation and metabolic disorders. Nature. 2006;444(7121):860-867. doi:10.1038/nature05485

28. Gregor MF, Hotamisligil GS. Inflammatory mechanisms in obesity. Annu Rev Immunol. 2011;29:415-445. doi:10.1146/annurev-immunol $-031210-101322$

29. Bochud M, Marquant F, Marques-Vidal PM, et al. Association between C-reactive protein and adiposity in women. J Clin Endocrinol Metab. 2009;94(10):3969-3977. doi:10.1210/jc.20082428

30. Stoppa-Vaucher S, Dirlewanger MA, Meier CA, et al. Inflammatory and prothrombotic states in obese children of European descent. Obesity. 2012;20(8):1662-1668. doi:10.1038/oby.2012.85

31. Nicklas BJ, Ambrosius W, Messier SP, et al. Diet-induced weight loss, exercise, and chronic inflammation in older, obese adults: a randomized controlled clinical trial. Am J Clin Nutr. 2004;79 (4):544-551. doi:10.1093/ajcn/79.4.544

32. Yamauchi M, Nakano H, Maekawa $J$, et al. Oxidative stress in obstructive sleep apnea. Chest. 2005;127(5):1674-1679. doi:10.13 78/chest.127.5.1674

33. Pierce GL, Lesniewski LA, Lawson BR, Beske SD, Seals DR. Nuclear factor- $\{$ kappa $\}$ B activation contributes to vascular endothelial dysfunction via oxidative stress in overweight/obese middle-aged and older humans. Circulation. 2009;119(9):1284-1292. doi:10.1161/ CIRCULATIONAHA.108.804294

34. Das UN. Is obesity an inflammatory condition. Nutrition. 2001;17 (11-12):953-966. doi:10.1016/S0899-9007(01)00672-4

35. Yoo SK, Starnes TW, Deng Q, Huttenlocher A. Lyn is a redox sensor that mediates leukocyte wound attraction in vivo. Nature. 2011;480 (7375):109-112. doi:10.1038/nature10632
36. Shah AD, Denaxas S, Nicholas O, Hingorani AD, Hemingway H. Neutrophil counts and initial presentation of 12 cardiovascular diseases: a CALIBER Cohort Study. J Am Coll Cardiol. 2017;69 (9):1160-1169. doi:10.1016/j.jacc.2016.12.022

37. Bozkuş F, Dikmen N, Samur A, Bilal N, Atilla N, Arpağ H. Does the neutrophil-to-lymphocyte ratio have any importance between subjects with obstructive sleep apnea syndrome with obesity and without obesity. Tuberk Toraks. 2018;66(1):8-15. doi:10.5578/tt.66535

38. Pietzner M, Kaul A, Henning AK, et al. Comprehensive metabolic profiling of chronic low-grade inflammation among generally healthy individuals. BMC Med. 2017;15(1):210. doi:10.1186/s12916-0170974-6

39. Mehra R, Redline S. Sleep apnea: a proinflammatory disorder that coaggregates with obesity. J Allergy Clin Immunol. 2008;121 (5):1096-1102. doi:10.1016/j.jaci.2008.04.002

40. Jelic S, Lederer DJ, Adams T, et al. Vascular inflammation in obesity and sleep apnea. Circulation. 2010;121(8):1014-1021. doi:10.1161/ CIRCULATIONAHA.109.900357

41. Balagopal PB, de Ferranti SD, Cook S, et al. Nontraditional risk factors and biomarkers for cardiovascular disease: mechanistic, research, and clinical considerations for youth: a scientific statement from the American Heart Association. Circulation. 2011;123 (23):2749-2769. doi:10.1161/CIR.0b013e31821c7c64

42. Hafez M, El-Masry S, Musa N, et al. Relationship between visceral obesity and plasma fibrinogen in obese children. $J$ Pediatr Endocrinol Metab. 2016;29(3):289-296. doi:10.1515/jpem-20150264

43. Tripodi A, Chantarangkul V, Martinelli I, Bucciarelli P, Mannucci PM. A shortened activated partial thromboplastin time is associated with the risk of venous thromboembolism. Blood. 2004;104(12):3631-3634. doi:10.1182/blood-2004-03-1042

44. Chan P, Lin TH, Pan WH, Lee YH. Thrombophilia associated with obesity in ethnic Chinese. Int J Obes Relat Metab Disord. 1995;19 (10):756-759.
Risk Management and Healthcare Policy

\section{Publish your work in this journal}

Risk Management and Healthcare Policy is an international, peerreviewed, open access journal focusing on all aspects of public health, policy, and preventative measures to promote good health and improve morbidity and mortality in the population. The journal welcomes submitted papers covering original research, basic science, clinical \& epidemiological studies, reviews and evaluations, guidelines, expert opinion and commentary, case reports and extended reports. The manuscript management system is completely online and includes a very quick and fair peer-review system, which is all easy to use. Visit http://www.dovepress.com/testimonials.php to read real quotes from published authors. 